\title{
Effect of Diabetes Mellitus on the Sense of Hearing of Adult Population of Hyderabad
}

\author{
Muhammad Tarique Shaikh, Khalida Shaikh, Arsalan Ahmed Shaikh
}

\begin{abstract}
OBJECTIVE: To assess the hearing thresholds connection between Diabetes Mellitus (DM) and hearing impairment $(\mathrm{HI})$ among cases and controls.

METHODOLOGY: This case control study was conducted in Physiology department in collaboration of Department of ENT, Liaquat University of Medical and Health Sciences (LUMHS) Jamshoro from February to July 2017. Total 196 subjects were divided into two groups, 98 controls and 98 cases; the subjects were collected from the diabetic clinic LUMHS Hyderabad. They were included in the study after screening and ear examination. They all were exposed to pure tone audiometry by Audiometer MAICO 39 (Berlin, Germany). The pure tone conduction was measured at 7 octave wave frequencies at minimum intensity which was heard and the graph was plotted on Audiogram. Hearing thresholds among subjects and $\mathrm{HI}$ were investigated.

RESULTS: The data was analysed with Statistical Package for Social Sciences (SPSS) version 20. The occurrence of $\mathrm{HI}$ was $34 \%$ which were slight to moderate degree. Significantly higher difference was observed in right ear at $500,2000,4000,6000$ and $8000 \mathrm{~Hz}$ frequencies (p-value $=0.004,0.025,0.002,0.001$ and 0.001 ) respectively and in left ear highly significant difference was obtained at 500, 4000,6000 and $8000 \mathrm{~Hz}$ frequencies ( $p$-value $=0.017,0.023,0.001$ and 0.001 ) respectively among subjects.

CONCLUSION: The hearing Impairment was highly significant in cases as compared to controls and hearing threshold difference was significant mainly at higher frequencies between two groups.
\end{abstract}

KEY WORDS: Diabetes Mellitus, Hearing Impairment, Pure Tone Audiometry

This article may be cited as: Shaikh MT, Shaikh K, Shaikh AA. Effect of Diabetes Mellitus on the Sense of Hearing of Adult Population of Hyderabad. J Liaquat Uni Med Health Sci. 2020;19 (02):97-101. doi: 10.22442/jlumhs.201920670

\section{INTRODUCTION}

The Hearing loss defines as more than $25 \mathrm{~dB}$ hearing impairment as pure tone thresholds in the better ear, due to which a person may not hear, parts of words or all of words in general communication ${ }^{1}$. According to World Health Organization (WHO), 466 million people over the globe have $\mathrm{HI}$ represents $5 \%$ of the population of all continents over the earth, this number will increase to nearby 900 million in the next three decades ${ }^{1}$.

The external ear collects sound energy and middle ear modifies it for transmission to the cochlea; the interference with the transmission of the sound signal at any point between the external ear and the auditory complex can result in $\mathrm{HI}^{2}$. $\mathrm{HI}$ may be congenital or acquired. Genetic disorders, chronic loud noise exposure, chronic E.N.T infections, trauma to head, certain antibiotics and cytotoxic medicines, aging, and chronic metabolic disturbance like DM may cause $\mathrm{HI}^{3}$. $\mathrm{HI}$ has been categorised as slight, moderate, severe and profound. Disabling $\mathrm{HI}$ is to be named from grade 1 and above. Deaf people have profound $\mathrm{HI}^{1}$. Grades of hearing impairment in Decibel $(\mathrm{dB})$ according to WHO are following:

$0=$ NO LOSS $(0-25 \mathrm{~dB})$

$1=$ SLIGHT or MILD LOSS $(25-40 \mathrm{~dB})$

2= MODERATE LOSS $(41-60 \mathrm{~dB})$
$3=$ SEVERE LOSS $(61-80 \mathrm{~dB})$

$4=$ PROFOUND LOSS (81dB and above)

Diabetes mellitus (DM) is a non-communicable disease characterized by extracellular hyperglycaemia and intracellular hypoglycaemia caused by deficiency of insulin secretion, resistance of insulin to work or both $^{4,5}$. The prevalence of DM in Pakistan is $6.76 \%$ and ranked 7 th in the list of countries who has a major of DM and would be expected to take 4th place in the couple of decades ${ }^{6}$. According to International Diabetes Federation (IDF) 2017, 425 million cases of DM were registered all around the world and in next couple of decades it will rise up to 629 million $^{6}$.

The number of changes that are varied time to time in the vascular and nervous system can be linked to chronic complications of DM and cells like organ of corti over time by high blood glucose level leads to degeneration that inappropriately put impact on the quality of life ${ }^{3}$.The relationship between DM and $\mathrm{HI}$ was first described in a case reported by JORDAO in 1857. $\mathrm{HI}$ is one of the known complications of $\mathrm{DM}^{3}$.

Recent epidemiological studies have described an increased risk for $\mathrm{HI}$ in diabeticsand it generally targets high frequency tones ${ }^{7}$. The burden of DM is increasing day by day and different systems of the body are affected due to it. The youngsters are extensively diagnosed diabetic as the prevalence of 
$\mathrm{DM}$ is increasing. This study was designed to determine the hearing impairment in relation with DM in young adults to produce local data, the outcomes of which would be added to local data base and could be helpful for public awareness. It also provided the information to general practitioner for early management of DM and early ENT referral.

\section{METHODOLOGY}

This was a prospective Case control study was conducted in the department of Physiology in collaboration with the Diabetic clinic and Department of ENT Liaquat University of Medical \& Health Sciences from February to July 2017 on 196 subjects. Subjects were divided into two groups, 98 controls and 98 cases; All known Diabetic adults up-to 10 years duration of both gender divided in both control and cases age from 20-40 years, and who had given consent to be a part of the study were included in the study; While those who had Gestational DM, history of ototoxic drugs, head injury, ear trauma and disease, exposure to industrial or occupational noise, smoking, upper respiratory tract infection in the last one month and systemic disease like hypertension were excluded from the study. All data was recorded in a predesigned proforma.

After taking an informed written consent by all participants their ear examinations and pure tone audiometry was conducted according to the guidelines of the British society of audiology ${ }^{8}$. A detailed history was taken and thorough physical examination was done; Blood pressure was recorded by aneroid sphygmomanometer (Certeza, Germany) capillary random blood glucose checked by glucometer (Accuchek, Roche Germany). The ears' examination was done by Otologist in which normal landmarks and mobility of tympanic membrane were assessed afterwards hearing test was performed by tuning fork (T.F) $512 \mathrm{~Hz}$ i.e Rinne's, Weber's and absolute bone conduction.

Blood sugar was checked before Audiometry was done in the noise free environment by an Audiometer (MAICO-M 39, Germany); Supra-aural headphones (TDH-39, Germany) were to be placed on both ears of subjects after removing any obstruction that could intervene with placement of the earphone cushions over the external auditory meatus.

A better ear was tested first; the responses were given when the tones heard by raising the corresponding hand of the subjects'. The most commonly used procedure for hearing threshold is called a modified Hughson Westlake procedure ${ }^{9}$. This is defined as at first $40 \mathrm{~dB}$ intensity stimuli was given at 1000 frequency $\mathrm{HZ}$ to make identification about the stimuli. One by one each ear threshold was sensed of the volunteers by 10 down and 5 up method at 1000 , $2000,4000,6000,8000,500$ and $250 \mathrm{HZ}$ in respective order. Repeated the same 10 down and 5 up method for 3 times; Two out of three ascending responses indicated the hearing threshold of that ear for respective frequency in $\mathrm{HZ}$.

At audiogram, right ear hearing threshold indicated by $\mathrm{O}$ and left ear by $\mathrm{X}$ symbol. $\mathrm{HI}$ was classified according to $\mathrm{WHO}^{8}$. About 20-25 minutes were consumed in audiometric examination of each subjects' then they were free to go.

The data was analysed with SPSS version 20 . Frequency and percentages of categorical variables were calculated and statistical differences were tested by applying Chi-square test; quantitative variables were computed by mean \pm standard deviation and statistical differences were tested by applying t-test. $p$ value $<0.05$ was considered to be significant.

\section{RESULTS}

Mean RBS for control subjects $(n=98)$ was $123.61 \pm 5.89$ and for cases $(n=98)$ it was $272.54 \pm 38.96$. There was a significant difference between two groups. ( $p$-value $=0.0001$ ). Table $\mathbf{l}$.

The mean right ear hearing threshold was significantly higher for cases as compared to controls. There was a significant difference noted in mean right ear hearing threshold among cases and controls at frequencies of $8000 \mathrm{~Hz}, 6000 \mathrm{~Hz}, 4000 \mathrm{~Hz}, 2000 \mathrm{~Hz}$ and $500 \mathrm{~Hz}(\mathrm{p}-$ values $=0.001, \quad 0.001, \quad 0.002, \quad 0.025, \quad 0.004$ respectively), However non-significant difference was found in mean right ear hearing threshold at frequencies of $1000 \mathrm{~Hz}$ and $250 \mathrm{HZ}$ ( $p$-values $=0.250$ and 0.189 respectively) between two groups. Table II. The mean left ear hearing threshold was significantly higher for cases as compared to controls. There was a significant difference noted in mean left ear hearing threshold among cases and controls at frequencies of $8000 \mathrm{~Hz}, 6000 \mathrm{~Hz}, 4000 \mathrm{~Hz}$, and $500 \mathrm{~Hz}$ ( $p$-value $=0.001$, $0.001,0.023$, and 0.017 respectively), while nonsignificant difference was found in mean left ear hearing threshold at frequencies of $2000 \mathrm{~Hz}, 1000 \mathrm{~Hz}$ and $250 \mathrm{HZ}$ (p-values $=0.352,0.387$ and 0.109 respectively) between two groups. Table III.

The degree of slight $\mathrm{HI}$ was noted in 33 subjects out of them 32 were cases and 01 was control and only 01 moderate degree of $\mathrm{HI}$ was observed that belonged to a cases group. A significant difference observed in the degree of $\mathrm{HI}$ between two groups ( $p$-value $=0.001$ ). Table IV.

TABLE I: DISTRIBUTION OF SUBJECTS ACCORDING TO MEAN RBS $(\mathrm{mg} / \mathrm{dl})(\mathrm{n}=196)$

\begin{tabular}{|ccc|}
\hline Subjects & $\begin{array}{c}\text { RBS } \\
\text { (Mean } \pm \text { SD) }\end{array}$ & P-Value \\
\hline Controls $(n=98)$ & $123.61 \pm 5.89$ & \multirow{2}{*}{$0.0001^{*}$} \\
\hline Cases $(n=98)$ & $272.54 \pm 38.96$ & \\
\hline
\end{tabular}

*Significant 
Muhammad Tarique Shaikh, Khalida Shaikh, Arsalan Ahmed Shaikh

TABLE II. MEAN RIGHT EAR HEARING

THRESHOLDS AMONG SUBJECTS $(n=196)$

\begin{tabular}{cccc}
\hline $\begin{array}{c}\text { Right ear } \\
\text { Hearing } \\
\text { threshold }\end{array}$ & $\begin{array}{c}\text { Controls } \\
\mathbf{n}=98\end{array}$ & $\begin{array}{c}\text { Cases } \\
\mathbf{n}=98\end{array}$ & P-Value \\
\cline { 2 - 3 } & $21.57 \pm 2.38$ & $22.46 \pm 2.65$ & 0.189 \\
\hline $250 \mathrm{HZ}$ & $20.52 \pm 1.57$ & $22.50 \pm 2.71$ & $0.004^{*}$ \\
\hline $500 \mathrm{HZ}$ & $20.00 \pm 0.00$ & $20.42 \pm 1.41$ & 0.250 \\
\hline $1000 \mathrm{HZ}$ & $20.00 \pm 0.00$ & $21.19 \pm 2.14$ & $0.025^{*}$ \\
\hline $2000 \mathrm{HZ}$ & $21.52 \pm 2.79$ & $23.10 \pm 3.00$ & $0.002^{*}$ \\
\hline $4000 \mathrm{HZ}$ & $20.83 \pm 1.90$ & $26.41 \pm 4.82$ & $0.001^{*}$ \\
\hline $6000 \mathrm{HZ}$ & $20.00 \pm 0.00$ & $24.09 \pm 4.05$ & $0.001^{*}$ \\
\hline $8000 \mathrm{HZ}$ & & & \\
\hline
\end{tabular}

*Significant

TABLE III. MEAN LEFT EAR HEARING

THRESHOLDS AMONG SUBJECTS $(n=196)$

\begin{tabular}{cccc}
\hline $\begin{array}{c}\text { Left ear } \\
\text { Hearing } \\
\text { threshold }\end{array}$ & $\begin{array}{c}\text { Controls } \\
\mathbf{n = 9 8}\end{array}$ & $\begin{array}{c}\text { Cases } \\
\mathbf{n = 9 8}\end{array}$ & P-Value \\
\cline { 2 - 3 } & $20.95 \pm 2.01$ & $22.03 \pm 2.80$ & 0.109 \\
\hline $250 \mathrm{HZ}$ & $20.00 \pm 0.00$ & $21.80 \pm 2.64$ & $0.017^{*}$ \\
\hline $500 \mathrm{HZ}$ & $20.23 \pm .1 .23$ & $20.75 \pm 1.80$ & 0.387 \\
\hline $1000 \mathrm{HZ}$ & $20.41 \pm 1.44$ & $20.94 \pm 1.97$ & 0.352 \\
\hline $2000 \mathrm{HZ}$ & $21.42 \pm 2.34$ & $22.20 \pm 2.91$ & $0.023^{*}$ \\
\hline $4000 \mathrm{HZ}$ & $20.83 \pm 1.91$ & $26.19 \pm 5.41$ & $0.001^{*}$ \\
\hline $6000 \mathrm{HZ}$ & $20.66 \pm 1.75$ & $24.27 \pm 3.99$ & $0.001^{*}$ \\
\hline $8000 \mathrm{HZ}$ & & & \\
\hline
\end{tabular}

*Significant

TABLE IV. DESCRIPTIVE STATISTICS OF DEGREE OF HEARING IMPAIRMENT AMONG CASES AND CONTROL $(n=196)$

\begin{tabular}{|c|c|c|c|c|}
\hline $\begin{array}{l}\text { Degree of hearing } \\
\text { Impairment }\end{array}$ & $\begin{array}{c}\text { Controls } \\
n=98\end{array}$ & $\begin{array}{c}\text { Cases } \\
\mathrm{n}=98\end{array}$ & $\begin{array}{c}\text { Total } \\
\mathrm{n}=196\end{array}$ & P-value \\
\hline Normal $(\leq 25 \mathrm{~dB})$ & 97 & 65 & 162 & \\
\hline Slight (26-40dB) & 01 & 32 & 33 & \\
\hline Moderate $(41-60 \mathrm{~dB})$ & 00 & 01 & 01 & $0.001^{*}$ \\
\hline Severe $(61-80 \mathrm{~dB})$ & 00 & 00 & 00 & \\
\hline Profound $(>81 \mathrm{~dB})$ & 00 & 00 & 00 & \\
\hline
\end{tabular}

*Significant

\section{DISCUSSION}

In the present study, significant $\mathrm{HI}$ was found in cases as compared to controls; it was slight to moderate degree. A Significant difference was observed in $\mathrm{HI}$ at higher frequencies. Almost $34 \%$ of cases have got slight to moderate $\mathrm{HI}$ at higher frequencies in the present study. Similar findings were made by Farooq M 2013 ${ }^{10}$, Irshad M 2015 $5^{11}$, Majeed S $2018^{12}$, Ramlakhan M $2016^{13}$, Joshi KD $2017^{14}$ and Mishra R $2016^{15}$, but these findings were in contrast to findings by Vignesh SS $2015^{16}$. Farooq M $2013^{10}$ found $79 \%$ $\mathrm{HI}$ in diabetics, while Ramlakhan M $2016^{13}$ found $58 \%$ $\mathrm{HI}$ in diabetics at higher frequencies. Mishra R 2016 ${ }^{15}$ conducted study in India have got slight to moderate $\mathrm{HI}$ in cases through pure tone audiometry from frequencies 2000 to $8000 \mathrm{~Hz}$ with normal mean hearing thresholds below frequencies $2000 \mathrm{~Hz}$ with mean age of 37.3 years. Majeed $S 2018^{12}$ in a 310 cases study observed a significant $\mathrm{HI}$ in about $46 \%$ of cases $^{12}$, while Ndubuisi Nwosu J $2017^{7}$ in a 224 cases study showed a significant $\mathrm{HI}$ in about $47 \%$ of cases. Irshad M $2015^{11}$ in a 286 cases study observed a significant $\mathrm{HI}$ in about $12.2 \%$ of cases, while LermanGarber I et $\mathrm{al}^{17}$ observed $21.7 \%$ hearing impairment in 46 cases; he had found significantly higher mean hearing thresholds at all frequencies in cases than control subjects and significant bilateral threshold difference above $2000 \mathrm{~Hz}$, these findings are comparable with findings observed in the present study. Yikawe SS $2017^{18}$ showed significantly higher mean hearing thresholds at higher frequencies in cases. In-Hwan Oh et $\mathrm{al}^{19}$, Vijayasundaram V $2014^{20}$ and Ndubuisi Nwosu J 2017 reported that incidence of $\mathrm{HI}$ was two times higher in cases than controls which was mostly high frequency impairment.

Tabatabaei $F 2016^{21}$ demonstrated a significant difference in mean hearing thresholds in cases. Forogh B $2013^{22}$ found significantly higher hearing thresholds at 2000,4000 , and $8000 \mathrm{~Hz}$ for both ears among cases as compared to control subjects with mean age of 35 years but within normal hearing ranges; the findings correlate with the present study.

Significantly higher hearing thresholds have been observed by In-Hwan Oh et $\mathrm{al}^{19}$ at $6000 \mathrm{~Hz}$ in cases among 20-40 years of age; the finding likewise in the current study pointing out that $\mathrm{HI}$ commences at high frequencies in younger then progress at normal frequency of human speech, later on involvement of low frequency hearing thresholds. Misra $V 2013^{23}$ in comparative study observed significantly higher mean hearing thresholds among cases at 6000 and 8000 $\mathrm{Hz}$; these findings are in agreement with the present study.

It would be easy to know $\mathrm{HI}$ by screening that can be slight which otherwise could not be detected. Diabetics did not know about their HI that's why they could not self notice and might be missed ${ }^{18}$, that has been demonstrated in the current study during pure tone audiometry. During early phases of $\mathrm{HI}$ daily happenings are not disturbed and at daily speaking range of 500 to $2000 \mathrm{~Hz}$ the organs are not destabilised but it would be hard to make difference between speech judgement and consonants sounds leading to sound perception compromise ${ }^{19}$. 
The present study would be relevant due to inclusion of younger subjects by which many confounding variables which may cause $\mathrm{HI}$ were avoided. Number of studies have described the prime relation between $\mathrm{DM}$ and $\mathrm{HI}$ mostly for the high frequency tones which were subclinical in the younger age subjects by which other causes of the same are not common ${ }^{13,15,16 .}$

\section{CONCLUSION}

Hearing impairment was significantly more common in cases as compared to controls. Mean right and left ear hearing threshold was significantly more common at higher frequencies in cases as compared to controls. Audiometric testing should be recommended in all diabetics at the time of diagnosis to screen out subclinical hearing impairment and prevent further loss.

Ethical permission: Liaquat University of Medical \& Health Sciences ERC letter No. LUMHS/REC/-512, dated: 05-05-2016.

Conflict of Interest: There is no conflict of interest to report by any of the authors.

Funding: There was no funding from any agency or institution.

\section{REFERENCES}

1. Organization $\mathrm{WH}$. Global estimates on prevalence of hearing loss. World Health Organization. 2018; Geneva Switzerland. Available from: https:// www.who.int/ deafness/estimates/en/

2. Horikawa C, Kodama S, Tanaka S, Fujihara K, Hirasawa R, Yachi $Y$, et al. Diabetes and risk of hearing impairment in adults: A meta-analysis. J Clin Endocrinol Metabol. 2013; 98(1): 51-8. doi:10.1210/jc.2012-2119.

3. Bhaskar KN, Chalihadan S, Vaswani R, Rehaman CPA. Clinical and audiometric Assessment of Hearing Loss in Diabetes Mellitus. Int J Sci Study. 2014; 2 (4): 1-16

4. Organization WH, Federation ID. Definition and diagnosis of diabetes mellitus and intermediate hyperglycaemia. WHO/ IDF Consultation. Geneva: WHO Press. 2006; Available from: https://www.who.int/diabetes/publications/ diagnosis_diabetes2006/en/

5. Yagihashi S, Inaba W, Mizukami H. Dynamic pathology of Islet endocrine cells in type-2 diabetes: $\beta$-cell growth, death, regeneration and their clinical implications. J Diabetes Investig. 2016; 7(2): 155-65. doi: 10.1111/jdi.12424.

6. Karuranga S, Fernandes JD, Huang Y, Malanda B. Diabetes Atlas 8th Edition. International Diabetes Federation Press, 2017. Available from: www.diabetesatlas.org.

7. Ndubuisi Nwosu J, Nkechi Chime E. Hearing Thresholds in adult Nigerians with Diabetes Mellitus: a case-control study. Diabetes Metab
Syndr Obes. 2017; 10:155-160. doi:10.2147/ DMSO.S128502

8. British Society of Audiology. Recommended procedure pure-tone air-conduction and bone conduction threshold audiometry with and without masking. British Society of Audiology (BSA), 80 Brighton Road, Reading, Berkshire, RG6 1PS, UK. 2011. Available from: www.thebsa.org.

9. Baiduc R, Poling GL, Hong O, Dhar S. Clinical measures of auditory function: The cochlea and Beyond. Dis Mon. 2013; 59(4): 147-156. doi:10.1016/j.disamonth.2013. 01.005

10. Farooq M, Ahmed A, Mehmood Z, Waheed A. Frequency of sensory neural hearing loss ( $\mathrm{SNHL})$ in type 1 and type 2 diabetics patients. Pak J Otolaryngol. 2013; 29(3): 87-89.

11. Irshad $M$, Ishaque $M$, Mahmood $K$, Dar UF. Association between sensorineural hearing loss and complicated diabetes mellitus. Pak $\mathrm{J}$ Med Health Sci. 2015; 9(4): 1384-6.

12. Majeed S, Mumtaz N, Saqulain G. Prevalence of sensorineural hearing loss among patients of diabetes mellitus in southern Punjab, Pakistan. J Shifa Tameer Millat Univ. 2018; 1(1): 32-6. doi:10.32593/jstmu/Vol1.Iss1.36.

13. Ramlakhan M, Divij S, Sonkhya N. Evaluation of Hearing loss in patients with type-2 Diabetes Mellitus. Int J Res Med Sci. 2016; 4 (6): 2281-7. doi:10.18203/2320-6012. ijrms.20161800.

14. Joshi KD, Galagali JR, Singh SK. A Study of Diabetes Mellitus on auditory system. Rom J Diabetes Nutr Metab Dis. 2017; 24(1): 49-55.

15. Mishra R, Sanju HK, Kumar P. Auditory Temporal Resolution in Individuals with Diabetes Mellitus Type 2. Int Arch Otorhinolaryngol. 2016; 20(4): 327-330. doi:10.1055/s-0035-1571207

16. Vignesh SS, Jaya V, Muraleedharan A. Identifying Early Onset of Hearing Loss in Young Adults with Diabetes Mellitus Type-2 Using High Frequency Audiometry. Indian J Otolaryngol Head Neck Surg. 2015; 67(3): 234-7. doi:10.1007/s12070-014 -0779-2.

17. Lerman-Garber I, Cuevas-Ramos D, Valdes S, Erniquez L, Lobato $M$, Osornio $M$, et al. Sensorineural Hearing Loss - A Common finding in early onset Type-2 Diabetes Mellitus. Endocr Pract. 2012;18(04): 549-57. doi:10.4158/ EP11389.OR.

18. Yikawe SS, Robert Iseh K, Sabir AA, Solomon JH, Manya C, Aliyu N. Effect of Duration of Diabetes Mellitus on Hearing Threshold among type-2 Diabetics. Indian J Otol. 2017; 23(2): 113-6.

19. In-Hwan Oh, Lee JH, Park DC, Kim M, Chung J, Kim S, et al. Hearing Loss as a Function of Aging and Diabetes Mellitus: A Cross Sectional Study. PLoS One. 2014; 9(12): 1-12. doi: 10.1371/ journal.pone.0116161.

20. Vijayasundaram V, Karthikeyan $P$, Coumare $\mathrm{N}$. 
Pure tone audiometric evaluation in Non-insulin dependent Diabetic patients. Int J Cur Rev 2014; 6(8): 63-70.

21. Tabatabaei F, Razzaghi R, Soleimani Z, Nouri S. The risk factors of hearing loss in Diabetes Mellitus. J Res Med Dent Sci. 2016; 4(4): 51-6. doi:10.5455/jrmds.20164410.

22. Forogh B, Zeinolabedini R, Akbari M, Mianehsaz
E. Evaluation of hearing in middle-aged patients with Diabetes Mellitus Type-2. J Biomed Sci Eng. 2013; 6: 16-19. doi:10.4236/jbise.2013.65A004.

23. Misra V, Agarwal CG, Bhatia N, Shukla GK. Sensorineural Deafness in Patients of Type-2 Diabetes Mellitus in Uttar Pradesh: A Pilot Study. Indian J Otolaryngol Head Neck Surg. 2013; 65 (Suppl 3): 532-6. doi:10.1007/s12070-011-0442-0.

AUTHOR AFFILIATION:

Dr. Muhammad Tarique Shaikh

(Corresponding Author)

Department of Physiology

Liaquat University of Medical \& Health Sciences

(LUMHS), Jamshoro, Sindh-Pakistan.

Email: tariqued2@gmail.com

\section{Dr. Khalida Shaikh}

Associate Professor

Department of Physiology

LUMHS, Jamshoro, Sindh-Pakistan.

\section{Dr. Arsalan Ahmed Shaikh}

Assistant Professor

Department of Ear Nose \& Throat (ENT)

LUMHS, Jamshoro, Sindh-Pakistan. 